\title{
Weather-based forecasting of mosquito-borne disease outbreaks in Canada
}

\author{
$\mathrm{NH}$ Ogden ${ }^{1 *}$, LR Lindsay², A Ludwig', AP Morse ${ }^{3}, \mathrm{H}$ Zheng ${ }^{4}, \mathrm{H}$ Zhu $^{5}$
}

\begin{abstract}
Early warning systems to predict infectious disease outbreaks have been identified as a key adaptive response to climate change. Warming, climate variability and extreme weather events associated with climate change are expected to drive an increase in frequency and intensity of mosquito-borne disease (MBD) outbreaks globally. In Canada, this will mean an increased risk of endemic and emerging MBD outbreaks such as West Nile virus and other MBDs. The availability of timely information on the risk of impending MBD outbreaks has important public health implications, by allowing implementation of mosquito control measures and targeted communications regarding the need for increased personal protective measures-before an outbreak occurs. In Canada, both mechanistic and statistical weather-based models have been developed to predict West Nile virus outbreaks. These include models for different species of mosquitoes that transmit West Nile virus in different geographical areas of Canada. Although initial results have been promising, further validation and assessment of forecasting skill are needed before wide scale implementation. Weather-based forecasting for other emerging MBDs in Canada, such as Eastern equine encephalitis, may also be feasible.
\end{abstract}

Suggested citation: Ogden NH, Lindsay LR, Ludwig A, Morse AP, Zheng H, Zhu H. Weather-based forecasting of mosquito-borne disease outbreaks in Canada. Can Commun Dis Rep 2019;45(5):127-32.

https://doi.org/10.14745/ccdr.v45i05a03

Keywords: mosquito-borne diseases, weather-based forecasting, West Nile virus, Eastern equine encephalitis, climate change, Canada

\section{Introduction}

The United Nations Intergovernmental Panel on Climate Change has identified the development of early warning systems as a key adaptation strategy to deal with the health risks of climate change (1). One type of early warning system is weather-based forecasting, or the use of weather data to predict the risk of a specific infectious disease outbreak in a specific area. Research on a wide range of mosquito-borne diseases (MBDs), including West Nile virus (WNV), malaria and Rift Valley fever, have proven the concept of weather-based forecasting (2). The United States' (US) National Oceanic and Atmospheric Administration has initiated a program to facilitate validation of various forecasting models (3).

In Canada, the most common MBD is the West Nile virus infection. This virus is endemic in the southernmost parts of Canada and human cases have been detected across much of the country. The WNV causes a range of mild to severe illness, and occasionally deaths, each year (4). Other MBDs, including the California serogroup viruses (snowshoe hare virus and Jamestown Canyon virus) and Cache Valley virus, are endemic in Canada. There is some evidence that not only may these MBDs be more common in humans in Canada than previously thought $(5,6)$ but they may also increase with climate change (7). In addition, there is increasing concern that other MBDs, which are currently endemic in the US, may expand northward into Canada with climate change (8). Furthermore, there will be an increased risk that exotic MBDs, such as dengue and chikungunyaand the mosquitoes that carry them-will become established in Canada. With climate change, these exotic mosquitoes, having been introduced from abroad via increased international passenger travel and increased international shipping, may now find the environmental conditions that they need to survive (9).
This work is licensed under a Creative Commons Attribution 4.0 International License.

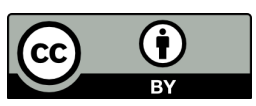

Affiliations

${ }^{1}$ National Microbiology Laboratory, Public Health Agency of Canada, St. Hyacinthe, QC

${ }^{2}$ National Microbiology Laboratory, Public Health Agency of Canada, Winnipeg, MB

${ }^{3}$ School of Environmental Sciences, University of Liverpool, Liverpool, UK

${ }^{4}$ Centre for Food-borne, Environmental \& Zoonotic Infectious Diseases, Public Health Agency of Canada, Ottawa, ON

${ }^{5}$ Department of Mathematics and Statistics and Laboratory of Mathematical Parallel Systems, York University, Toronto, ON

*Correspondence: nicholas.ogden@canada.ca 
Globally, many MBDs demonstrate epidemic behaviour (10). This "boom and bust" epidemiological pattern is also seen with WNV in Canada. This means there are epidemics of WNV in some years and only small numbers of cases in other years. In 2007, 2,215 cases were reported (mostly from an outbreak affecting the prairie provinces) and in 2010, only five cases were reported and in 2012, 428 cases were reported (mostly from an outbreak affecting Ontario and Quebec) (4). This epidemic behaviour is thought to be due mostly to the effects of the weather on mosquito lifecycles and WNV transmission. In 2007, a mild winter followed by a warm and wet spring provided ideal weather for multiplication of Culex tarsalis (the main WNV vector in the Prairies), while hot summer weather in eastern Canada in 2012 may have enhanced WNV transmission by $C x$. pipiens and $C x$. restuans (the main vectors in eastern Canada) (4).

The methods currently used to monitor WNV in Canada are mosquito surveillance (to detect the levels of environmental hazard), detection of infection in sentinel animals and human case surveillance (which also assesses the severity of the disease burden). The environmental hazard is the number of humanbiting, infected mosquitoes present in a given area (4). Increases in both the number of infected mosquitoes and number of human cases typically occur in the late summer to early autumn (4). If these increases occur early in the season, or the increases in infected mosquitoes and/or human cases are higher than usual, it may indicate the start of an epidemic. When the signal of an increased WNV risk is identified, it triggers two local public health responses. The first response is mosquito control, including the use of larvicides and (where acceptable) adulticides (11), and the second response is public awareness, including the promotion of personal protective measures (12).

The drawback of the current WNV surveillance system is that it can detect outbreaks only after they have started. By understanding how weather affects mosquito lifecycles and virus transmission, it is theoretically possible to predict MBD outbreaks and enable a public health response to begin before an outbreak actually occurs $(3,13)$.

The objective of this overview is to describe the concepts, methods and status of weather-based forecasting for WNV in Canada, and identify the next steps needed to implement forecasting as a public health tool.

\section{Concepts of weather-based forecasting}

Weather-based forecasting for MBDs uses knowledge of the influence of ambient temperature and precipitation on the survival and lifecycles of mosquitoes. For example, ambient temperature affects the rate of development of mosquito eggs, larvae and pupae, with warmer temperatures accelerating the mosquito lifecycle. Warmer temperatures also accelerate the extrinsic incubation period, or how fast mosquito-borne pathogens ingested by adult mosquitoes multiply and are disseminated from the gut to the salivary glands from whence they can be transmitted to humans (14). Higher temperatures can also affect the activity level of the adult mosquitoes. In addition to changes in temperature, changes in precipitation can also affect mosquito abundance. Excess precipitation often leads to standing water, and this can enhance mosquito replication, because standing water is required for the larval and pupal stages of the mosquito. As a further complication to weatherbased forecasting, droughts turn drainage channels in urban and sub-urban areas into standing water, which then becomes mosquito breeding habitat. Therefore, some outbreaks in these areas are associated with dry as well as hot weather.

Weather-based forecasting looks for conditions associated with MBD outbreaks, and these conditions are particular to a specific mosquito, a specific MBD and a specific geographic area.

Figure 1 summarizes a hypothetical MBD outbreak, with and without the timely public health response informed by weather-based forecasting. Using conventional surveillance techniques, the delay between the beginning of an outbreak and confirmation of the outbreak can be one to four weeks (one week for testing of infected mosquito and four weeks for clinical diagnosis, laboratory testing and reporting of an infected patient) (Figure 1A). Thus, by the time the outbreak is confirmed, it is largely over. In contrast, Figure 1B shows the possible effects of an early (i.e. weather-based forecasting) response, which could trigger an early public health response, thereby reducing the number of infected mosquitoes and hence the severity of the MBD outbreak.

\section{Types of forecasting models}

Weather-based forecasting is done using either mechanistic or statistical models. The forecasting models that have been developed for Canada are described below.

\section{Mechanistic models}

The simplest mechanistic types of models are those that employ simple indices of temperature, obtained from laboratory studies, for key points of the mosquito lifecycle (e.g. limits for mosquito activity) or virus transmission cycles. One method (15), developed and implemented in Saskatchewan, uses a simple measurement of the accumulated days with temperatures above a threshold of $14.3^{\circ} \mathrm{C}$, which is the threshold temperature for development of WNV in the prairie mosquito vector, $C x$. tarsalis. These data are then used to estimate the timing of high risk to the public. Similar data are used in public information pieces by public health organizations in Quebec and Ontario, although these have not yet been assessed as early warning systems $(16,17)$. Most mechanistic models are mathematical reconstructions of mosquito lifecycles and pathogen transmission cycles. These models incorporate known effects of temperature and precipitation on the mosquito lifecycle, and effects of 
Figure 1: How weather-based forecasting facilitates an early public health response to a mosquito-borne disease outbreak

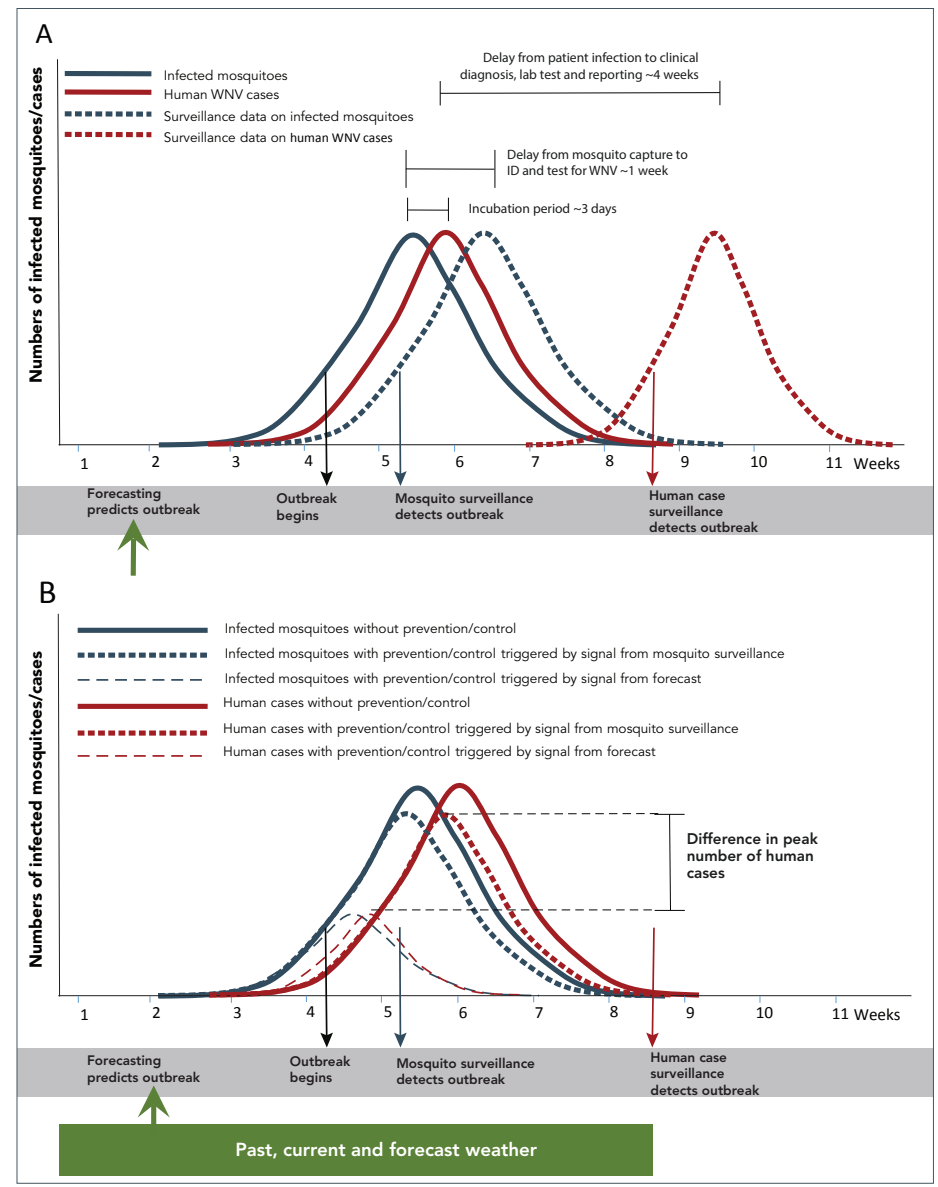

Abbreviations: ID, identify; WNV, West Nile virus

Figure legend: In panel $A$, the numbers of infected mosquitoes and human infections at the time they occur is shown by solid lines graph, and the numbers of infected mosquitoes and human infections at the time they are detected by surveillance systems is shown by dashed line graphs. The reasons for, and duration of, delays between occurrence and detection by surveillance are shown by horizontal lines. In panel $B$, the numbers of infected mosquitoes and human infections in the absence of public health intervention (shown by the solid line graphs), compared against the numbers if interventions are started in response to signals from mosquito surveillance (shown by dotted lines) or by forecasting (shown by dashed line graphs). The black arrow indicates the start of an outbreak; the green, blue and red arrows indicate the signals of an outbreak provided by forecasting, and mosquito and human case surveillance respectively. The green rectangle indicates the past current and forecast weather used to develop the mosquito forecast

temperature on the extrinsic incubation period, to predict how recent and forecast weather may affect mosquito abundance and the proportion of these mosquitoes that will be infected in coming weeks to forecast the hazard to humans (18). For these models to be effective in predicting risk in a particular location, where prevention and control may have to be implemented, they need to be detailed, with many parameters involved in estimating weather-based and weather-independent influences on the mosquito lifecycles and pathogen transmission cycles. These models have been developed largely for forecasting exotic MBD outbreaks, such as malaria in Africa (19). In Canada, there is currently only limited detailed, quantitative knowledge of how temperature and rainfall affect different mosquito lifecycles.

Only one mechanistic weather forecasting model that uses reconstruction of mosquito lifecycles has been developed in Canada. Yu et al. developed a mechanistic model of the lifecycle of $C x$. pipiens and Cx. restuans mosquitoes in eastern Canada (20), which incorporates data on the effects of temperature on mosquito development and survival. This model performed well against mosquito surveillance data used in its validation.

\section{Statistical models}

Statistical models use statistical "pattern matching" to identify how current and recent temperature and rainfall affect the abundance of mosquitoes and the proportion of these mosquitoes that are infected with pathogens $(21,22)$. Pattern matching is developed with recent weather data and the current mosquito surveillance data to identify the quantitative relationship between the numbers of mosquitoes (and proportions of mosquitoes infected) on any one day and the accumulated or mean temperature and precipitation values for specific mosquito capture sites during the preceding weeks and months. Using this relationship, and taking into account the expected weather over the coming weeks (data that are obtained from weather forecasting models), the abundance of mosquitoes and proportion infected can be forecast (23).

In Canada, four weather-based forecasting statistical models for WNV have been developed, in the three regions of Canada where the risk is greatest: southern parts of the prairie provinces; southern Ontario; and southern Quebec. One model was developed in Saskatchewan to forecast both the numbers of $C x$. tarsalis mosquitoes and the proportion infected in the Prairies, using temperature and precipitation data as predictors (23). This model was loosely validated against the numbers of human cases in two months of one year, and predicted a spatial pattern of risk for these two months that was consistent with the observed pattern of incidence of human cases. The other three statistical models have been developed in Quebec $(22)$ and Ontario $(21,24)$ where the vectors of WNV are Cx. pipiens and Cx. restuans mosquitoes. All models used temperature and precipitation data as predictors, and were validated against mosquito surveillance data $(21,22,24)$. One of the Ontario models (21) has undergone a trial in the Toronto area by the Peel Region Public Health Unit (25). Both predicted and observed risks were low during the trial period.

\section{Validation approaches}

There are a number of different approaches to the validation of weather-based forecasting models. One approach is to compare the data from traditional surveillance methods (of mosquitoes, viruses and human cases) with model-predicted values obtained using mechanistic or statistical models based on local weather data. For the studies conducted in Canada to date, such entomological validation suggests that both the mechanistic and statistical modelling approaches to weather-based forecasting show great promise. There is evidence of spatial heterogeneity in how the mosquito populations respond to weather at a local scale. This is likely due to the modulation of temperature and/ or precipitation by local topography, resulting in changes in the 
habitat of immature mosquitoes $(16,26)$. Accounting for variation in the topography improves the performance of the models (22-24).

A more public health-oriented approach to validation is an estimation of the probability that the model correctly predicts outbreak versus non-outbreak conditions (known as the "forecasting skill" of the weather-based forecasting model). The World Health Organization's aim for malaria forecasts is to have acceptable skill in forecasting $60 \%$ of malaria outbreaks over the subsequent two weeks (13). A number of metrics are used to define this acceptable skill, including those based on receivingoperator characteristic (27), which quantify the capacity of the model to have acceptable sensitivity (i.e. low false negatives-so will miss few outbreaks) and acceptable specificity (i.e. low false positive-so will raise few false alarms). The extent to which missed outbreaks and false alarms are tolerable is a decision of public health professionals and policy makers, who would ultimately decide on a model's public health utility.

\section{Discussion}

The Intergovernmental Panel on Climate Change has identified the need for early warning systems, such as weather-based forecasting, to detect MBD outbreaks. Several weather-based forecasting models have been developed in Canada for WNV, outbreaks of which are anticipated to become more frequent with climate change. Initial validation research suggests that these models show great promise. These models have the potential to provide short range forecasting of risk (i.e. of one or a few weeks ahead). This type of forecasting may be too short range to be useful in triggering proactive reduction measures to kill immature mosquitoes (larviciding), but would certainly allow for both reactive reduction measures to kill adult mosquitoes (adulticiding) as well as alerts to the public to enhance adoption of personal protection. Usually the rates of adoption of personal protection methods are low (28-30), in part, because of a perception of low risk by the public. Weather-based forecasting offers the possibility of raising awareness and heightening risk perception amongst the public, and so could increase adoption of personal protection measures at times and places where impending risk is high.

Weather-based forecasting of WNV would be a useful adjunct to our public health response to improve protection of Canadians from emerging and re-emerging MBDs by providing the earliest possible warning of outbreaks. However, there are limits to its application. First, this type of forecasting cannot replace surveillance in humans, mosquitoes and/or sentinel animals, as outbreaks can be due to factors independent of (or only indirectly associated with) weather. These factors include changes in herd immunity of wild animal reservoir host populations or emergence of novel strains of pathogens associated with MBDs
(4). Maintaining mosquito surveillance is also prudent as it would allow for regular validation of forecasting models. Second, early signals of impending MBD risk, provided by forecasting models, demand that public health systems, methods and actions can respond rapidly to these risks, although in most jurisdictions this type of public health response is already in place.

Forecasting of WNV and other MBD epidemics on a national scale in Canada is a possibility for the future. Research needed before implementation includes prospective validation and assessment of forecasting skill (and how that may vary geographically), adoption and application by end users and the development of methods to best communicate this type of risk to the public. To achieve these aims will require resourced, concerted field, laboratory and computer simulation studies by local, provincial/territorial and federal organisations working in collaboration with entomologists, ecologists, epidemiologists and mathematicians in academic research institutions.

To date, weather-based forecasting has only been attempted for WNV in Canada as there is currently too little knowledge of the ecology of other MBDs endemic to Canada (e.g. the California serogroup viruses), and little systematic surveillance data with which to calibrate and validate models. But this may be possible in the future with more systematically collected data.

In general, weather-based models have greater forecasting skill over short time scales (i.e. the short term or extended forecasts of a few days to a week) (21), and decreasing forecasting skill over longer time scales (i.e. long range or seasonal forecasts of weeks to months) (31). However, some longer range forecast models have met the World Health Organization's target of $60 \%$ skill in forecasting (32). The weather-based forecasting models that have been most successful at forecasting on a seasonal timescale are those that aim to predict variations in the magnitude of the normal seasonal peaks of endemic MBD, such as malaria, when the magnitude of those peaks are determined by cyclical global climate phenomena, particularly the El Niño Southern Oscillation (33). This kind of forecasting has not yet been explored for WNV in Canada, in part due to the short (circa 10 year) time series of surveillance data (34).

\section{Conclusion}

The future implementation of weather-based forecasting of WNV, and potentially other MBDs, will allow for earlier alerts of impending outbreaks. As outbreaks of MBDs are anticipated to increase in frequency and/or intensity with climate change, these alerts will allow for more accurate and timely public health response with a concomitant reduction in public health impact. Adoption of the idea of weather-based forecasting, and more widespread practical implementation by public health in Canada, depends on further validation and assessment of 
forecasting skill, as well as exploration of the degree to which forecasting models need to be calibrated for specific geographic areas. Development of weather-based forecasting for other endemic and emerging MBDs should be possible with increased knowledge of the ecology of these diseases, and with more systematic surveillance.

\section{Authors' statement}

$\mathrm{NHO}$ led writing the article, $\mathrm{NHO}$ and $\mathrm{AL}$ conceptualized the article, all authors (NHO, AL, APM, LRL, HZ) contributed to drafting the paper.

\section{References}

1. Smith KR, Woodward A, Campbell-Lendrum D, Chadee DD, Honda Y, Liu Q, Olwoch JM, Revich B, Sauerborn R, Aranda C, Berry H, Butler C, Chafe Z, Cushing L, Ebi KL, Kjellstrom T, Kovats S, Lindsay G, Lipp E, McMichael T, Murray V, Sankoh O, O’Neill M, Shonkoff SB, Sutherland J, Yamamoto S. Climate Change 2014: Impacts, Adaptation, and Vulnerability. Part A: Global and Sectoral Aspects. Contribution of Working Group II to the Fifth Assessment Report of the Intergovernmental Panel on Climate Change. Cambridge, UK and New York, USA: Cambridge University Press; 2014. Human Health: Impacts, Adaptation, and Co-Benefits. p. 709-54. www.ipcc.ch/site/assets/ uploads/2018/02/WGIIAR5-Chap11_FINAL.pdf

2. Zinszer K, Verma AD, Charland K, Brewer TF, Brownstein JS, Sun Z, Buckeridge DL. A scoping review of malaria forecasting: past work and future directions. BMJ Open 2012 Nov;2(6):e001992. DOl PubMed

3. Semenza JC. Prototype early warning systems for vector-borne diseases in Europe. Int J Environ Res Public Health 2015 Jun;12(6):6333-51. DOl PubMed

4. Public Health Agency of Canada. Surveillance of West Nile Virus. Ottawa (ON): PHAC; 2018. (Accessed 2018-10-25). www.canada.ca/en/public-health/services/diseases/west-nilevirus/surveillance-west-nile-virus.html

5. Kulkarni MA, Lecocq AC, Artsob H, Drebot MA, Ogden NH. Epidemiology and aetiology of encephalitis in Canada, 19942008: a case for undiagnosed arboviral agents? Epidemiol Infect 2013 Nov;141(11):2243-55. DOl PubMed

6. Drebot MA. Emerging mosquito-borne bunyaviruses in Canada. Can Commun Dis Rep 2015 Jun;41(6):117-23. DOI PubMed

7. Ludwig A, Zheng $H$, Vrbova L, Drebot M, Iranpour M, Lindsay $\mathrm{R}$. Increased risk of endemic mosquito-borne diseases in Canada under climate change. Can Commun Dis Rep 2019;45(4):90-7. DOI

\section{Conflict of interest}

None.

\section{Funding}

This work was supported by the Public Health Agency of Canada.
8. $\quad \mathrm{Ng} \mathrm{V}$, Rees EE, Lindsay RL, Drebot MA, Brownstone T, Sadeghieh T, Khan SU. Could exotic mosquito-borne diseases emerge in Canada with climate change? Can Commun Dis Rep 2019;45(4):98-107. DOI

9. Ogden NH, Gachon P. Climate change and infectious diseases: what can we expect? Can Commun Dis Rep 2019;45(4):76-80. DOI

10. Githeko AK, Lindsay SW, Confalonieri UE, Patz JA. Climate change and vector-borne diseases: a regional analysis. Bull World Health Organ 2000;78(9):1136-47. PubMed

11. Reisen W, Brault AC. West Nile virus in North America: perspectives on epidemiology and intervention. Pest Manag Sci 2007 Jul;63(7):641-6. DOl PubMed

12. Public Health Agency of Canada. Prevention of West Nile virus. Ottawa (ON): PHAC; 2018. www.canada.ca/en/publichealth/services/diseases/west-nile-virus/prevention-west-nilevirus.htm

13. World Health Organization. 2005-2010 Roll Back Malaria: Global strategic plan. Geneva (CH): WHO; 2005. www1. paho.org/hq/dmdocuments/2010/mal-2005-cor-1.pdf

14. Ogden NH, Lindsay LR. Effects of climate and climate change on vectors and vector-borne diseases: ticks are different. Trends Parasitol 2016 Aug;32(8):646-56. DOI PubMed

15. Government of Saskatchewan. West Nile Virus Surveillance Report, 2018: June 23. http://publications.gov.sk.ca/ documents/13/107167-West-Nile-Virus-Surveillance-ReportWeek-of-June-23-2018.pdf

16. Public Health Ontario. West Nile Virus surveillance. www publichealthontario.ca/en/dataandanalytics/pages/wnv.aspx

17. Institut national de santé publique du Québec. Rapport de surveillance du virus du Nil occidental et autres arbovirus transmis par les moustiques au Québec. www.inspq.qc.ca/ sites/default/files/publications/2455_surveillance_virus_nil_ occidental_arborovius.pdf 
18. Hoshen MB, Morse AP. A weather-driven model of malaria transmission. Malar J 2004 Sep;3:32. DOI PubMed

19. Diouf I, Rodriguez-Fonseca B, Deme A, Caminade C, Morse AP, Cisse M, Sy I, Dia I, Ermert V, Ndione JA, Gaye AT. Comparison of malaria simulations driven by meteorological observations and reanalysis products in Senegal. Int J Environ Res Public Health 2017 Sep;14(10):E1119. DOI PubMed

20. Yu D, Madras N, Zhu H. Temperature-driven population abundance model for Culex pipiens and Culex restuans (Diptera: culicidae). J Theor Biol 2018 Apr;443:28-38. DOl PubMed

21. Wang J, Ogden NH, Zhu H. The impact of weather conditions on Culex pipiens and Culex restuans (Diptera: Culicidae) abundance: a case study in Peel Region. J Med Entomol. 2011;48(2):468-75. PubMed

22. Ripoche M, Campagna C, Ludwig A, Ogden NH, Leighton PA. Short-term forecasting of daily abundance of West Nile virus vectors Culex pipiens-restuans and Aedes vexans based on weather conditions and larvicide use in southern Québec (Canada). J Med Entomol 2019;56(3):1-14. DOI

23. Chen CC, Epp T, Jenkins E, Waldner C, Curry PS, Soos C. Modeling monthly variation of Culex tarsalis (Diptera: Culicidae) abundance and West Nile Virus infection rate in the Canadian Prairies. Int J Environ Res Public Health 2013 Jul;10(7):3033-51. DOl PubMed

24. Gao X, Cao YR, Ogden N, Aubin L, Zhu HP. Mixture Markov regression model with application to mosquito surveillance data analysis. Biom J 2017 May;59(3):462-77. DOI PubMed

25. Laboratory of Mathematical Parallel Systems. Mosquito Abundance and West Nile Risk Yearly Forecasting for Peel Region. www.lamps.yorku.ca/yearly-forecast-graphs

26. Yusa A, Berry P, J Cheng J, Ogden N, Bonsal B, Stewart R, Waldick R. Climate change, drought and human health in Canada. Int J Environ Res Public Health 2015 Jul;12(7):8359412. DOI PubMed
27. MacLeod DA, Jones A, Di Giuseppe F, Caminade C, Morse AP. Demonstration of successful malaria forecasts for Botswana using an operational seasonal climate model. Environ Res Lett. 2015;10(4): 044005. https://iopscience.iop. org/article/10.1088/1748-9326/10/4/044005/meta DOI

28. Centers for Disease Control and Prevention (CDC). Knowledge, attitudes, and behaviors about West Nile virus-Connecticut, 2002. MMWR Morb Mortal Wkly Rep 2003 Sep;52(37):886-8. www.cdc.gov/mmwr/preview/mmwrhtml/ mm5237a4.htm PubMed

29. Wilson SD, Varia M, Lior LY; Field Epidemiology Summer Course. West Nile Virus: the buzz on Ottawa residents' awareness, attitudes and practices. Can J Public Health 2005 Mar-Apr;96(2):109-13. PubMed

30. Trumbo CW, Harper R. Perceptual influences on self-protective behavior for West Nile virus, a survey in Colorado, USA. BMC Public Health 2015 Jun;15:557. DOI PubMed

31. Government of Canada. Skill of the Deterministic Forecast System. 2019. https://weather.gc.ca/saisons/skill_e.html

32. Lauderdale JM, Caminade $C$, Heath $A E$, Jones AE, MacLeod DA, Gouda KC, Murty US, Goswami P, Mutheneni SR, Morse AP. Towards seasonal forecasting of malaria in India. Malar J 2014 Aug;13:310. DOI PubMed

33. Thomson MC, Doblas-Reyes FJ, Mason SJ, Hagedorn R, Connor SJ, Phindela T, Morse AP, Palmer TN. Malaria early warnings based on seasonal climate forecasts from multi-model ensembles. Nature 2006 Feb;439(7076):576-9. DOI PubMed

34. Manore CA, Davis J, Christofferson RC, Wesson D, Hyman $\mathrm{JM}$, Mores CN. Towards an early warning system for forecasting human west nile virus incidence. PLoS Curr 2014 Mar;6. DOl PubMed 